This item was submitted to Loughborough's Research Repository by the author.

Items in Figshare are protected by copyright, with all rights reserved, unless otherwise indicated.

\title{
In-vitro oral digestion of microfluidically produced monodispersed W/O/W food emulsions loaded with concentrated sucrose solution designed to enhance sweetness perception
}

\section{PLEASE CITE THE PUBLISHED VERSION}

https://doi.org/10.1016/j.jfoodeng.2019.109701

\section{PUBLISHER}

Elsevier

\section{VERSION}

AM (Accepted Manuscript)

\section{PUBLISHER STATEMENT}

This paper was accepted for publication in the journal Journal of Food Engineering and the definitive published version is available at https://doi.org/10.1016/j.jfoodeng.2019.109701.

\section{LICENCE}

CC BY-NC-ND 4.0

\section{REPOSITORY RECORD}

Alnuumani, Ruqaiya, Goran Vladisavljevic, Miroslaw Kasprzak, and Bettina Wolf. 2019. "In-vitro Oral Digestion of Microfluidically Produced Monodispersed W/O/W Food Emulsions Loaded with Concentrated Sucrose Solution Designed to Enhance Sweetness Perception". Loughborough University. https://hdl.handle.net/2134/9757097.v1. 


\section{In-vitro oral digestion of microfluidically produced monodispersed $\mathrm{W} / \mathrm{O} / \mathrm{W}$ food}

emulsions loaded with concentrated sucrose solution designed to enhance sweetness perception

Ruqaiya Al nuumani ${ }^{\mathrm{a}}$, Goran T. Vladisavljević, ${ }^{\mathrm{a},}$, Miroslaw Kasprzak ${ }^{\mathrm{b}, 1}$, Bettina Wolf ${ }^{\mathrm{b}, 2}$

a Department of Chemical Engineering, Loughborough University, Loughborough LE11 3TU, United Kingdom.

${ }^{\mathrm{b}}$ School of Biosciences, University of Nottingham, Loughborough LE12 5RD, United Kingdom.

${ }^{1}$ Present address: Research Group, Devro Plc, Moodiesburn, Glasgow, G69 0JE, United Kingdom.

2 Present address: School of Chemical Engineering, University of Birmingham, Birmingham B15 2TT, United Kingdom.

*Corresponding author. Tel.: +44 1509 222518. E-mail address: g.vladisavljevic@lboro.ac.uk (G.T. Vladisavljević).

\section{Graphical Abstract}
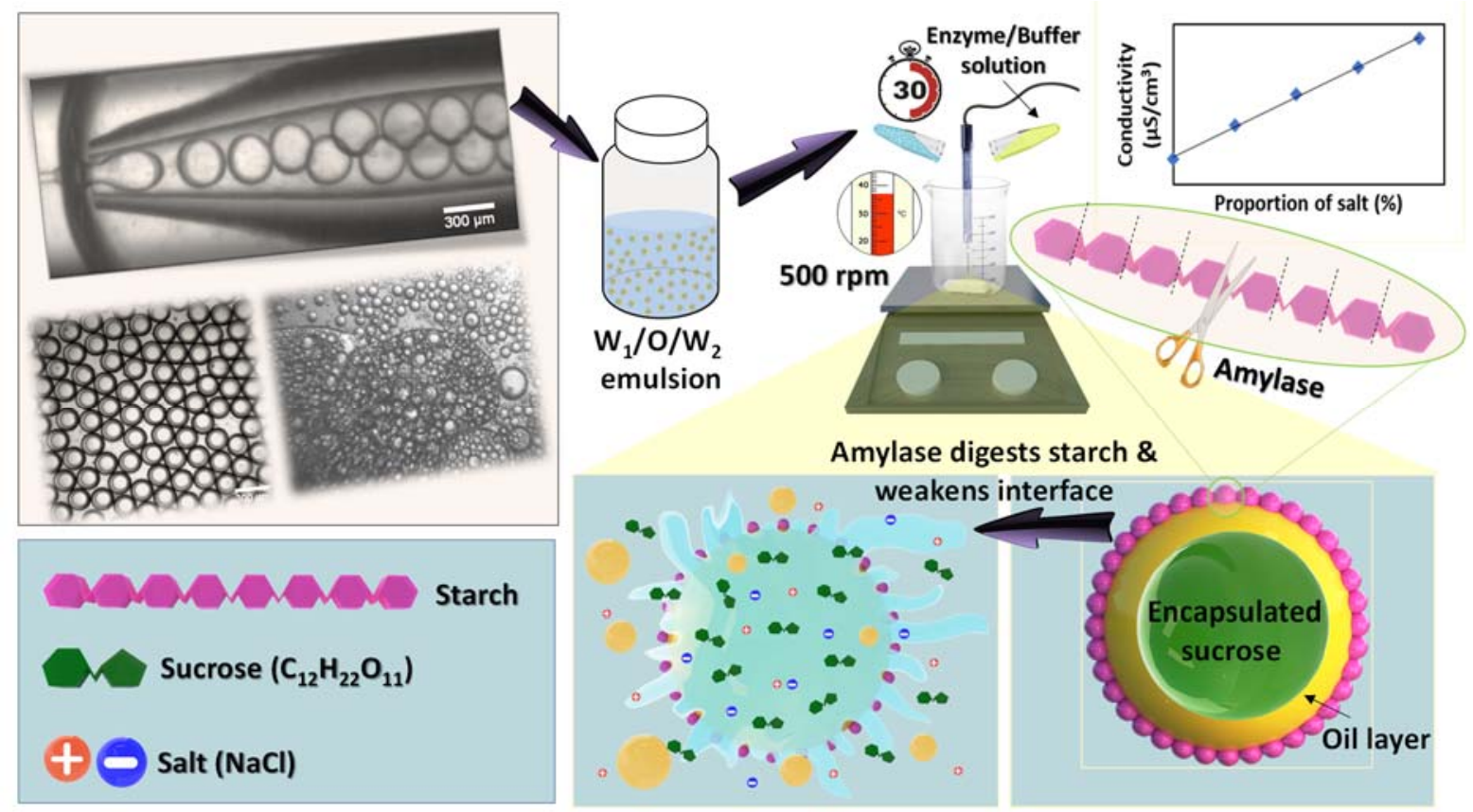

Abstract. Monodispersed $\mathrm{W}_{1} / \mathrm{O} / \mathrm{W}_{2}$ emulsions consisting of sunflower oil droplets containing a single large internal droplet or numerous small internal droplets of concentrated sucrose solution were prepared by microfluidic emulsification. The external droplet interface was 
stabilized by waxy rice starch, which hydrolyzes during oral processing thereby releasing the encapsulated sucrose solution to the proximity of taste receptors imparting a higher sweetness perception compared to adding the same amount of sugar to the bulk phase. The sucrose release was tracked by adding $\mathrm{NaCl}$ to the internal phase as a conductivity tracer. Core/shell droplets containing $50 \mathrm{wt} \%$ sucrose and $1.5 \mathrm{wt} \% \mathrm{NaCl}$ in the internal phase, $1.40-2.86 \mathrm{wt} \%$ polyglycerol polyricinoleate (PGPR) in the middle phase, and $4 \mathrm{wt} \%$ gelatinized waxy rice starch in the external phase were produced with $100 \%$ encapsulation efficiency and showed stability against coalescence for at least two months, because the gelatinized starch acted as a highly efficient Pickering stabilizer. The sucrose release from the inner droplets during in-vitro oral processing at $37^{\circ} \mathrm{C}$ for $30 \mathrm{~s}$ with $50 \mathrm{U} / \mathrm{mL} \alpha$-amylase increased from $16 \%$ to $49 \%$ when the PGPR concentration in the oil phase was reduced from $2.86 \mathrm{wt} \%$ to $0.7 \mathrm{wt} \%$. Core/shell droplets were less stable during storage when the surface-active molecularly dissolved octenyl succinic anhydride (OSA) modified starch was selected as stabilizer although the oil droplets were smaller due to the lower interfacial tension at the external interface. $\mathrm{W}_{1} / \mathrm{O} / \mathrm{W}_{2}$ emulsion consisting of numerous internal droplets coalesced during storage in one day and released $91 \%$ of sucrose during in-vitro oral processing.

Keywords: Encapsulation, Microfluidics, W/O/W emulsion, In-vitro oral digestion, Food emulsions, Sweetness perception enhancement.

\section{Highlights}

- Monodisperse W/O/W drops with $50 \mathrm{wt} \%$ sucrose in the inner phase were produced

- $\mathrm{W} / \mathrm{O} / \mathrm{W}$ emulsion was designed to break during in vitro digestion to release sucrose

- Varying fluid flow rates enabled to control the droplet size and shell thickness

- OSA starch NC46 led to smaller but less stable droplets than gelatinized starch

- Sucrose release from inner drops was higher at lower PGPR content in the oil phase 


\section{Introduction}

A multiple emulsion consists of internal droplets enclosed within larger droplets, which are themselves dispersed in an external continuous liquid phase. Multiple emulsions have been used in a variety of applications in food, pharmaceutical, and cosmetic industries (Benichou, et al. 2004; Vladisavljević et al. 2017; Kukizaki \& Goto 2007; Muschiolik 2007). They offer food processors a means to produce reduced-fat food products by replacing part of the oil with inner water droplets while maintaining a similar surface area of oil droplets (Muschiolik \& Dickinson 2017) and to produce reduced-sodium foods without compromising the saltiness perception by creating high salt gradients between inner and outer aqueous phase (Chiu et al. 2015). Multiple emulsions can also be used to improve sensory characteristics of foods by masking unpleasant taste and flavor, to protect sensitive ingredients, e.g. vitamins, antioxidants, probiotics, flavors, and minerals from environmental stresses such as oxygen, light, and pH and ionic strength changes (Jiménez-Colmenero 2013; Muschiolik 2007), and to achieve controlled release of active ingredients during oral processing and digestion (Benichou et al. 2004; Dickinson 2011; McClements et al. 2007; Muschiolik 2007; Chiu et al. 2015; Jiménez-Colmenero 2013; Muschiolik \& Dickinson 2017; Norton \& Norton 2010).

Multiple emulsions are usually produced by a two-step emulsification procedure where a single emulsion $\left(\mathrm{O}_{1} / \mathrm{W}\right.$ or $\left.\mathrm{W}_{1} / \mathrm{O}\right)$ is prepared and then re-emulsified in the second immiscible liquid $\left(\mathrm{O}_{2}\right.$ or $\left.\mathrm{W}_{2}\right)$ to prepare a $\mathrm{O}_{1} / \mathrm{W} / \mathrm{O}_{2}$ or $\mathrm{W}_{1} / \mathrm{O} / \mathrm{W}_{2}$ emulsion, respectively (McClements et al. 2007; Lamba et al. 2015). The first emulsification step is typically done using high energy inputs to prepare fine droplets while the second step is carried out at relatively low shear rates to prevent expulsion of internal droplets into the continuous phase. In conventional devices such as rotor-stator mixers and high-pressure homogenizers, the risk of losing the internal phase during secondary emulsification increases with increasing shear rate (Florence \& Whitehill, 1982). The highest encapsulation efficiency can be achieved at the lowest share rate, but it usually leads to highly polydisperse outer drops. Another problem with traditional devices is that the mean droplet size $\left(D_{p}\right)$ is difficult to control. Many properties of multiple emulsions such as their physicochemical stability, optical properties, rheological behavior, invitro digestibility, and release profile of encapsulated nutrients depend on $D_{p}$ (McClements, 2005). For fundamental investigations of the behavior of multiple emulsions, it is highly desirable to prepare multiple emulsions with tightly controlled droplet size that can easily be varied. 
Microfluidic emulsification is a new strategy of generating multiple emulsions, which offers unprecedented control over the size of both internal and external droplets and $~ 100 \%$ encapsulation efficiency within internal droplets (Vladisavljević et al. 2012; Al Nuumani et al. 2018). Microfluidic devices allow facile control over the number of internal droplets (Nabavi et al. 2017) and enable to enclose internal droplets of different solutions within the same outer drops (Sun et al. 2010). Furthermore, they provide an opportunity to achieve complex droplet architectures, such as bifacial (Janus) and triphasic (ternary) drops, and nested drops consisting of multiple concentric layers around each core (Vladisavljević et al. 2017). The majority of microfluidic devices make multiple emulsions using two sequential pinch-off events, usually in two consecutive T-junctions of alternating wettability (Okushima et al. 2004), which typically results in core/shell drops with thick shells (Abate et al. 2011).

There is a strong need to reduce fat, sugar and salt intake in our diet due to the health issues associated with their consumption (Knüppel et al., 2017). The use of multiple emulsions is a promising strategy to reduce the content of these potentially harmful ingredients in liquid and semi-liquid food products without compromising their taste. Two alternative approaches that can be used to enhance sweetness or saltiness perception in food products using multiple emulsions are: (a) to increase sugar or salt concentration in the continuous aqueous phase while keeping the tastant concentration within internal droplets at low levels and promoting in-mouth stability of multiple emulsion during oral processing (Buyukkestelli et al. 2019; Lad et al. 2012), and (b) to keep sugar or salt concentration in the continuous aqueous phase at low levels while increasing the tastant content within internal droplets to very high levels and promoting destabilization of the multiple emulsion during oral processing (Chiu et al. 2015). In the former case, the tastant is delivered to the taste receptors through the bulk of the food and taste intensity correlates to tastant concentration in the continuous phase. The role of the multiple emulsion here is to concentrate the tastant in the continuous phase, thereby enhancing its perception, while minimizing the amount of added lipid phase. In the latter approach, a water-soluble surfactant added to the continuous phase is designed to quickly break down when brought into contact with saliva, thus releasing high concentrations of tastant from the internal droplets in the proximity of taste receptors located on the tongue. Small pockets of concentrated tastant solution impart a higher perceived taste intensity compared to the case where all of the tastants are present in the external phase at moderate or low concentrations (Burseg et al. 2012).

The main objective of this study was to evaluate the feasibility of the sweetness enhancement technology based on burst release of sugar from internal droplets using multiple 
emulsions with a single large core droplet or numerous tiny internal droplets. For the first time, microfluidic devices composed of coaxial assemblies of borosilicate glass capillaries were used to encapsulate a concentrated sugar solution within starch-stabilized oil droplets. Core/shell droplets were produced using one dripping instability, which allows the shell thickness to be easily adjusted over a wide range (Nabavi et al. 2015). Borosilicate glass is a food-safe and inert material with superior optical transparency, which enables to monitor and control the drop generation process in real time.

Droplets were coated with either gelatinized waxy rice starch or molecularly dispersed, surface active, octenyl succinic anhydride (OSA) modified starch. The gelatinized waxy rice starch, which was not surface active, was adsorbed to the external water-oil interface $\left(\mathrm{O} / \mathrm{W}_{2}\right)$ as aggregated, insoluble starch, thus acting as Pickering stabilizer. Waxy rice starch was selected to reduce the complexity of the system, because waxy starch varieties contain almost $100 \%$ amylopectin, and not a mixture of amylopectin and amylose. Utilizing a starch emulsifier, the emulsion destabilizes during oral processing due to the mechanical actions of tongue and teeth combined with the enzymatic digestion of the starch, and the encapsulated sugar solution is released into the external phase. The sugar encapsulation efficiency, storage stability, and sugar release during in-vitro digestion were compared for emulsions with different formulations and droplet morphologies.

\section{Experimental}

\subsection{Chemicals}

A clean-label native waxy rice starch (Synergie Nutrylon) obtained from Ulrick and Short Ltd (Pontefract, UK) and octenyl succinic anhydride (OSA) modified waxy maize starch (NCreamer $^{\circledR} 46$, NC46, Univar, UK) were used as hydrophilic emulsifiers. Sunflower oil, table salt and sugar were purchased from a local supermarket (Tesco, UK). $\mathrm{NaCl}$ was added to the inner phase to track the release of aqueous phase from the oil phase. Polyglycerol polyricinoleate (GRINDSTED ${ }^{\circledR}$ PGPR, DuPont, Kettering, UK) was used as the lipophilic emulsifier. $\alpha$-Amylase from porcine pancreas with an enzymatic activity of $10 \mathrm{U} / \mathrm{mg}$ and sodium azide (antimicrobial agent) were supplied by Sigma Aldrich (Gillingham, UK). Sodium dihydrogen orthophosphate and disodium hydrogen orthophosphate obtained from Fisher Scientific were used to prepare phosphate buffer solution. All aqueous solutions were 
prepared using milli-Q water with a conductivity below $0.5 \mu \mathrm{S} / \mathrm{cm}$. Octadecyltrimethoxysilane (OTMS) and 2-[methoxy(polyethyleneoxy)propyl]trimethoxysilane (TMS-PEG) supplied by Fluorochem (Hadfield, UK) were used for surface treatment of glass capillaries.

\subsection{Fabrication of microfluidic devices}

A 2-phase glass device was used to produce a $\left(\mathrm{W}_{1} / \mathrm{O}\right) / \mathrm{W}_{2}$ emulsion composed of a multitude of inner droplets. A 3-phase glass device was used to produce a $\mathrm{W}_{1} / \mathrm{O} / \mathrm{W}_{2}$ emulsion containing only one large inner drop. A round capillary $(0.58 \mathrm{~mm}$ inner diameter and $1 \mathrm{~mm}$ outer diameter, Intracel, UK) was pulled using a Flaming/Brown micropipette puller (P-97, Sutter Instrument, UK) until it broke apart into two halves with tapered tips. Abrasive paper was used to polish both tips to the desired orifice size, which was checked using a microforge microscope (Narishige model MF-830). The capillary tips were cleaned with compressed air, washed with Milli-Q water and treated with TMS-PEG or OTMS to render them hydrophilic and hydrophobic, respectively. A square capillary with an inner width of $1.05 \pm 0.1 \mathrm{~mm}$ (AIT Glass, Rockaway, NJ) was attached to the microscope slide using a two-part epoxy glue. 2phase devices were assembled by inserting one round capillary with a hydrophilic tip into the square capillary. To assemble a 3-phase device, two round capillaries were inserted from each end of the square capillary at a desired distance from each other, which was checked using an inverted microscope onto which the device was placed. The tip of the injection capillary was made hydrophobic, while the collection capillary had a hydrophilic tip. Hypodermic needles with plastic hub were attached to the capillaries to introduce different liquids into the device. Each device was left for $24 \mathrm{~h}$ to ensure the glue was fully cured. These devices were recently replaced by more reproducible glue-free devices assembled using 3D printed capillary holders (Bandulasena et al. 2019). 


\subsection{Emulsion formation}

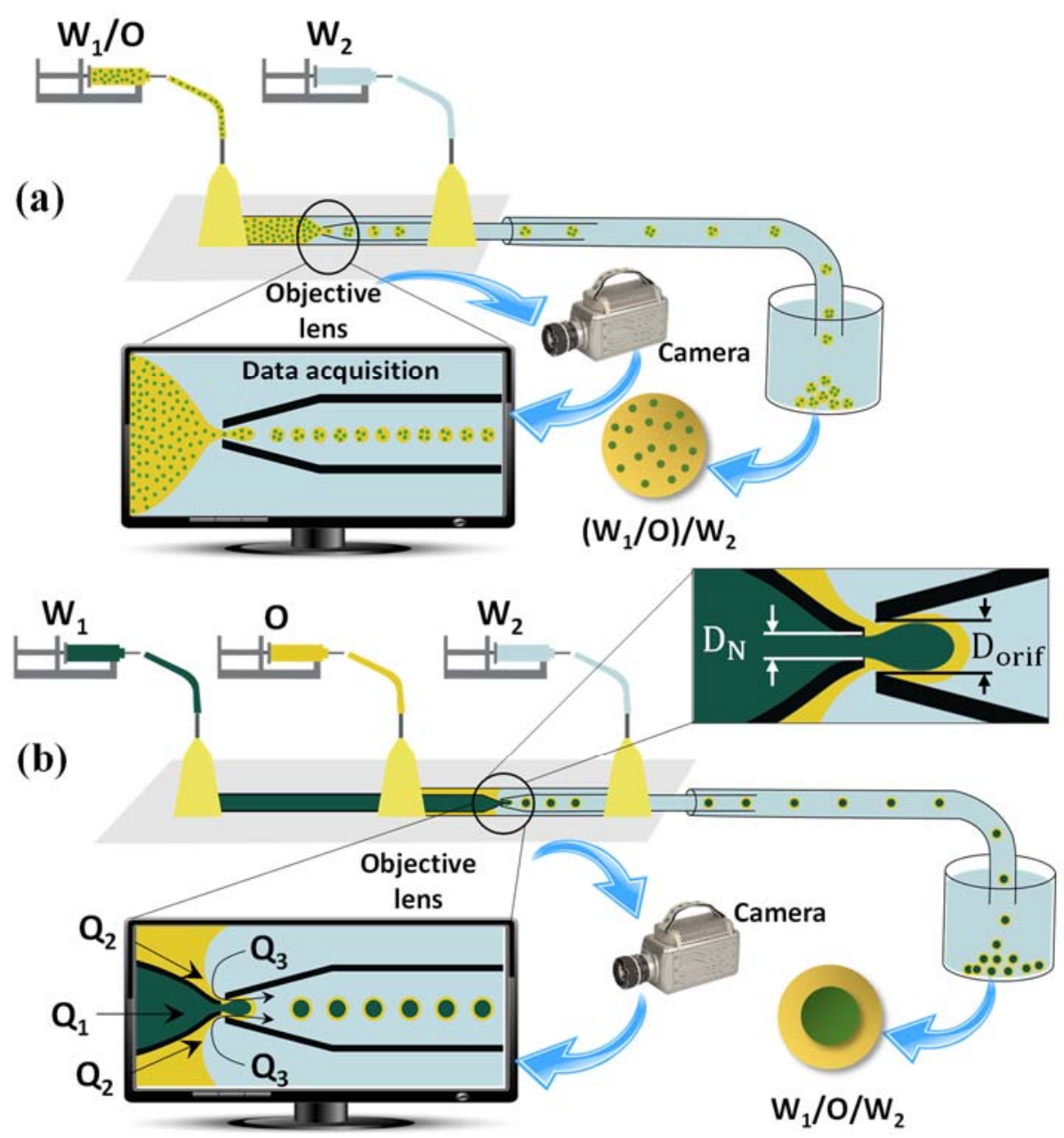

Figure 1. Schematic of the experimental setup consisting of glass capillary device, syringe pumps, inverted microscope and high-speed camera; (a) 2-phase device which requires two pumps for producing $\left(\mathrm{W}_{1} / \mathrm{O}\right) / \mathrm{W}_{2}$ multiple emulsion consisting of numerous tiny inner droplets dispersed in oil drops; (b) 3-phase device which requires three pumps for producing $\mathrm{W}_{1} / \mathrm{O}_{2} / \mathrm{W}$ multiple emulsion consisting of one large inner drop surrounded by oil shell.

A schematic of the experimental setup is shown in Figure 1. Gastight glass syringes with Luer-lock fitting (VWR Catalyst Company, UK) were loaded with feed solutions, installed on Harvard Apparatus 11 Elite syringe pumps and delivered through polyethylene medical tubing (0.86 mm I.D., $1.52 \mathrm{~mm}$ O.D., Fisher Scientific, UK) at controlled flow rates. The drop generation process, which depended on stream flow rates and device geometry, was observed and recorded using a GT Vision inverted microscope and Phantom V9.0 high-speed camera. ImageJ v.1.44 software (Wayne Rasband, National Institute of Health) was used to measure the average droplet diameter and frequency of droplet formation from the recorded pictures captured with a resolution of $768 \times 576$ pixels at 2000 frames per second. 
Multiple emulsion droplets with one large internal droplet were prepared upon the breakup of a compound jet composed of two coflowing liquids (the inner phase and the middle phase) in a 3-phase device. The inner phase was $1.5 \mathrm{wt} \% \mathrm{NaCl}$ and $50 \mathrm{wt} \%$ sucrose in water, the outer phase was a mixture of $25 \mathrm{wt} \%$ sucrose and $4 \mathrm{wt} \%$ gelatinized waxy rice starch in water, and the middle phase was $2.86 \mathrm{wt} \%, 1.4 \mathrm{wt} \%$ or $0.7 \mathrm{wt} \%$ PGPR in sunflower oil. Starch was gelatinized by mixing a suspension of starch in water with a high shear overhead mixer (LM5 fitted with emulsor screen, Silverson, Chesham, UK) at 8,000 rpm for $5 \mathrm{~min}$. During this process the temperature increased from ambient to $60-70{ }^{\circ} \mathrm{C}$ (Kasprzak et al. 2018).

Multiple emulsion droplets containing numerous small internal droplets were produced upon the breakup of the pre-formed $\mathrm{W}_{1} / \mathrm{O}$ emulsion in a 2-phase device. The primary $\mathrm{W}_{1} / \mathrm{O}$ emulsion was prepared using a high shear overhead mixer (LM5 fitted with emulsor screen, Chesham, UK). First, $2 \mathrm{~g}$ of PGPR was mixed with $68 \mathrm{~g}$ of sunflower oil for $2 \mathrm{~min}$ at 8,000 rpm to prepare the middle phase, followed by addition of $30 \mathrm{~g}$ of the inner phase containing $1.5 \mathrm{wt} \% \mathrm{NaCl}, 50 \mathrm{wt} \%$ sucrose and $0.02 \mathrm{wt} \% \mathrm{NaN}_{3}$ and shearing for $5 \mathrm{~min}$ at 8,000 $\mathrm{rpm}$.

\subsection{Encapsulation efficiency of sucrose, in-vitro digestion and emulsion stability}

Encapsulation efficiency of sugar in freshly produced multiple emulsions was estimated by incorporating $\mathrm{NaCl}$ as a conductometric tracer in the internal droplets. For in-vitro digestion, $9 \mathrm{~g}$ of the prepared emulsion were transferred into a $50 \mathrm{~mL}$ glass beaker containing a magnetic stirring bar followed by the addition of $9 \mathrm{~mL}$ of porcine amylase solution in phosphate buffer $(100 \mathrm{U} / \mathrm{mL}, 0.01 \mathrm{M})$ resulting in the final enzyme activity of $50 \mathrm{U} / \mathrm{mL}$ mixture. The mixture was stirred at $37^{\circ} \mathrm{C}$ and $500 \mathrm{rpm}$ for $30 \mathrm{~s}$ to mimic food processing in the oral cavity. The amount of internal phase released was determined based on the electric conductivity of the mixture before and after digestion. The calibration graphs were constructed by measuring the conductivity of $\mathrm{O} / \mathrm{W}$ emulsions with known amounts of salt in the external phase prepared with the same overall composition as the investigated emulsion samples. The detailed calibration procedure is provided in the supplementary information. The conductivity was measured using a Mettler Toledo Model inLab ${ }^{\circledR} 710$ conductivity meter with a measuring range of $0.01-500$ $\mathrm{mS} / \mathrm{cm}$, connected with a 4-pole platinum conductivity cell with a chemical resistant glass body. The stability of prepared emulsions against coalescence was estimated under stagnant conditions after 1 day, 7 days, and 60 days. The formation of a yellowish oil layer on top of the cream phase and clearly visible large oil droplets were taken as signs of coalescence. 


\section{Results and Discussion}

\subsection{Production of $\mathrm{W}_{1} / \mathrm{O} / \mathrm{W}_{2}$ emulsion}

Core/shell droplets with tunable size and shell thickness were produced by controlling the flow rates of the inner, middle and outer phase, $Q_{1}, Q_{2}$, and $Q_{3}$ (Figure 2), most notably the flow rate ratio $Q_{2} / Q_{1}$. The dimensionless parameter $\zeta$ can be used to predict the droplet generation regime (Nabavi et al. 2017b):

$$
\zeta=\left[\frac{C a_{1}{ }^{0.25}}{C a_{2}{ }^{0.57} C a_{3}{ }^{1.12}}\right]\left[\frac{D_{\text {orif }}}{D_{N}}\right]
$$

where $D_{\text {orif }}$ is the orifice diameter of the collection capillary, $D_{N}$ is the internal nozzle diameter of the injection capillary (see Fig. 1), whereas $C a_{1}, C a_{2}$, and $C a_{3}$ are the capillary numbers of the inner, middle and outer phase, respectively, given by (Nabavi et al. 2015):

$$
C a_{1}=\frac{\mu_{1} V_{1}}{\sigma_{12}} \quad C a_{2}=\frac{\mu_{2} V_{2}}{\sigma_{23}} \quad C a_{3}=\frac{\mu_{3} V_{3}}{\sigma_{23}}
$$

where $V_{1}=4 Q_{1} /\left(\pi D_{\mathrm{N}}^{2}\right), V_{2}=Q_{2} /\left(D_{c o}^{2}-\pi D_{c i}^{2} / 4\right)$, and $V_{3}=Q_{3} /\left(D_{c o}^{2}-\pi D_{c i}^{2} / 4\right)$ are the characteristic velocities of the inner, middle and outer phase, $D_{c i}$ is the internal height (or width) of the square capillary, and $D_{c o}$ is the outer diameter of the inner capillary.

At $\log \zeta>5.7$, a multiple emulsion was formed in the dripping regime (Fig. 2a-c), which resulted in monodisperse droplets, while jetting occurred at $\log \zeta<5.7$ (Fig. 2d). Based on Eq. (1), jetting occurs at very low $Q_{1}$ value or high $Q_{2}$ and $Q_{3}$ values. The reason for jetting in Fig. $2 \mathrm{~d}$ is the very low $Q_{1}$ value, resulting in large polydisperse droplets. According to the National Institute of Standards and Technology (NIST), "a particle size distribution may be considered monodisperse if at least $90 \%$ of the distribution lies within $5 \%$ of the median size". For a normal particle size distribution, it implies that droplets are monodisperse if $C V<3 \%$ (Vladisavljević et al. 2018), where $C V=D_{2} / \sigma$ is the coefficient of variation $\left(D_{2}\right.$ is the average diameter of external droplets and $\sigma$ is the standard deviation of their size).

At $Q_{2} / Q_{1}=3.3$ (Fig. 2a), the middle fluid jet was shorter than in Fig. $2 \mathrm{~d}$ with a shell thickness $\left(t_{s}\right)$ of $64 \mu \mathrm{m}$. With further decrease in $Q_{2} / Q_{1}$ below unity $(0.7$; Fig. 2b-c), droplets with thin shells $\left(t_{s}=11\right.$ and $\left.27 \mu \mathrm{m}\right)$ were formed close to the orifice. Therefore, the jet breakup length, droplet size, and shell thickness can be all controlled over a wide range by adjusting fluid flow rates. 


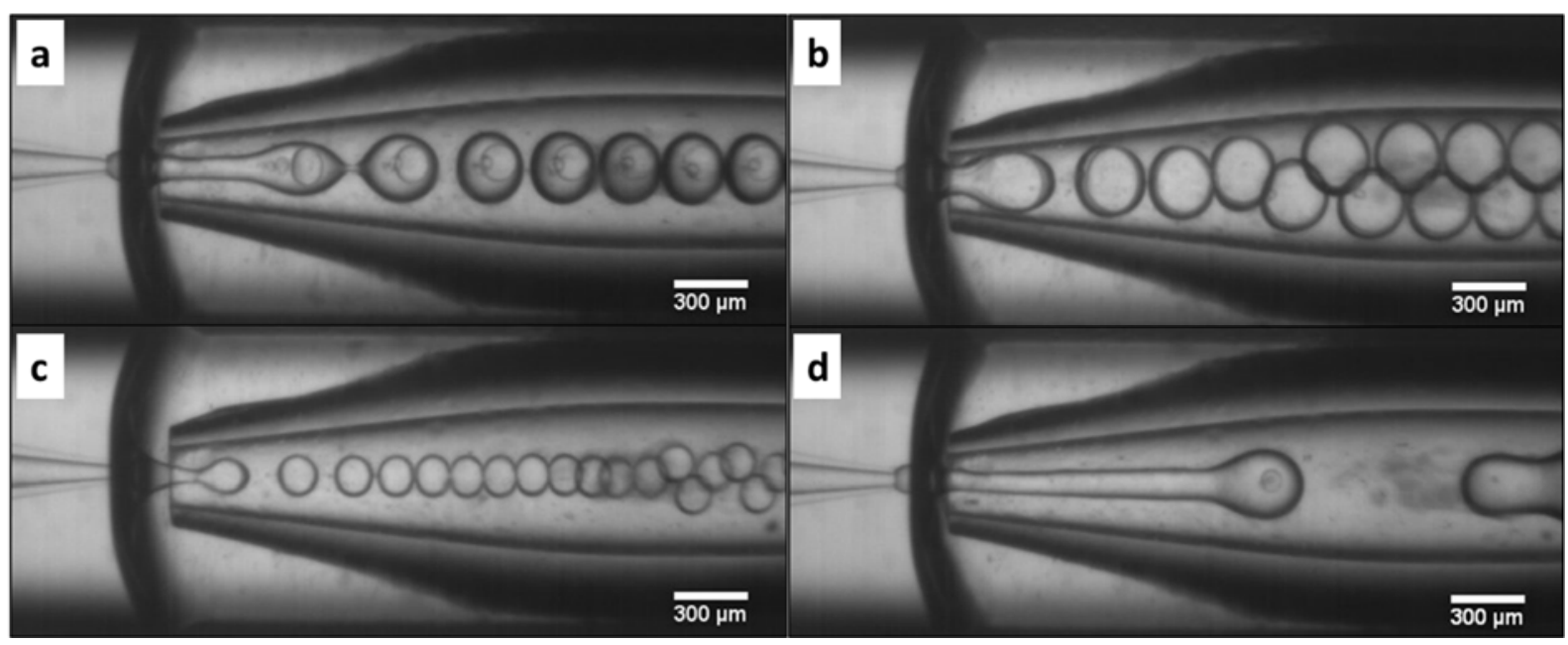

Figure 2. Formation of $\mathrm{W}_{1} / \mathrm{O} / \mathrm{W}_{2}$ emulsion in a 3-phase device with the nozzle diameter $D_{N}=$ $50 \mu \mathrm{m}$ and the orifice diameter $D_{\text {orif }}=250 \mu \mathrm{m}$ at different flow rates: (a) $Q_{1}=0.7 \mathrm{~mL} / \mathrm{h}, Q_{2}=$ $2.3 \mathrm{~mL} / \mathrm{h}, Q_{3}=7 \mathrm{~mL} / \mathrm{h}, D_{2}=286 \mu \mathrm{m}, D_{1}=157 \mu \mathrm{m}, t_{s}=64 \mu \mathrm{m}, f=9 \mathrm{~Hz}, C V=0.3 \%$; (b) $Q_{1}=2 \mathrm{~mL} / \mathrm{h}, Q_{2}=1.4 \mathrm{~mL} / \mathrm{h}, Q_{3}=3.5 \mathrm{~mL} / \mathrm{h}, D_{2}=299 \mu \mathrm{m}, D_{1}=242 \mu \mathrm{m}, t_{s}=27 \mu \mathrm{m}, f=$ $12 \mathrm{~Hz}, C V=0.2 \%$; (c) $Q_{1}=2 \mathrm{~mL} / \mathrm{h}, Q_{2}=1.4 \mathrm{~mL} / \mathrm{h}, Q_{3}=15.5 \mathrm{~mL} / \mathrm{h}, D_{2}=160 \mu \mathrm{m}, D_{1}=$ $138 \mu \mathrm{m}, t_{s}=11 \mu \mathrm{m}, f=38 \mathrm{~Hz}, C V=0.2 \%$; (d) $Q_{1}=0.1 \mathrm{~mL} / \mathrm{h}, Q_{2}=1.4 \mathrm{~mL} / \mathrm{h}, Q_{3}=7$ $\mathrm{mL} / \mathrm{h}$. The inner phase was $1.5 \mathrm{wt} \% \mathrm{NaCl}$ and $50 \mathrm{wt} \%$ sucrose in water, the middle phase was $2.86 \mathrm{wt} \%$ PGPR in sunflower oil and the outer phase was $25 \mathrm{wt} \%$ sucrose and $4 \mathrm{wt} \%$ gelatinised starch in water. The shell thickness $t_{s}$ was calculated as $\left(D_{1}-D_{2}\right) / 2$, where $D_{1}$ and $D_{2}$ and the diameters of inner and outer drop, respectively.

The effect of fluid flow rates on the droplet diameters, $D_{1}$ and $D_{2}$, and shell thickness, $t_{s}$ in the dripping regime is shown in Fig. 3.

As shown in Fig. 3a, an increase in $Q_{1}$ resulted in a small increase in $D_{1}$, due to higher inflow of the inner phase during jet pinch-off. However, $Q_{1}$ had no impact on the shear stress at the external oil-water interface and $D_{2}$ was unaffected by $Q_{1}$. Both trends resulted in a decrease in the shell thickness, $t_{s}$. The material balance equation can be written in the following form: $Q_{1}+Q_{2}=\left(\pi D_{2}^{3} / 6\right) f$, where $f$ is the drop generation frequency. Therefore:

$$
f=6 \pi^{-1} D_{2}^{-3}\left(Q_{1}+Q_{2}\right)
$$

Thus, at constant $D_{2}$ and $Q_{2}$, an increase in $Q_{1}$ led to an increase in $f$, as found in Fig. 3 a.

As shown in Fig. 3b, increasing $Q_{2}$ at constant $Q_{1}$ and $Q_{3}$ led to an increase in $D_{2}$, due to smaller shear stress at the external interface, while $D_{1}$ remained constant and thus, the oil shell became thicker. According to Eq. (3), $f$ increased with increasing $Q_{2}$.

Fig. 3c shows that increasing $Q_{3}$ reduced both $D_{1}$ and $D_{2}$ but by the same extent and the shell thickness remained constant. A decrease in $D_{1}$ and $D_{2}$ with an increase in $Q_{3}$ can be attributed to the increase in viscous stress exerted by the outer fluid to compound jet, which led to more frequent drop pinch-off and smaller droplets. 

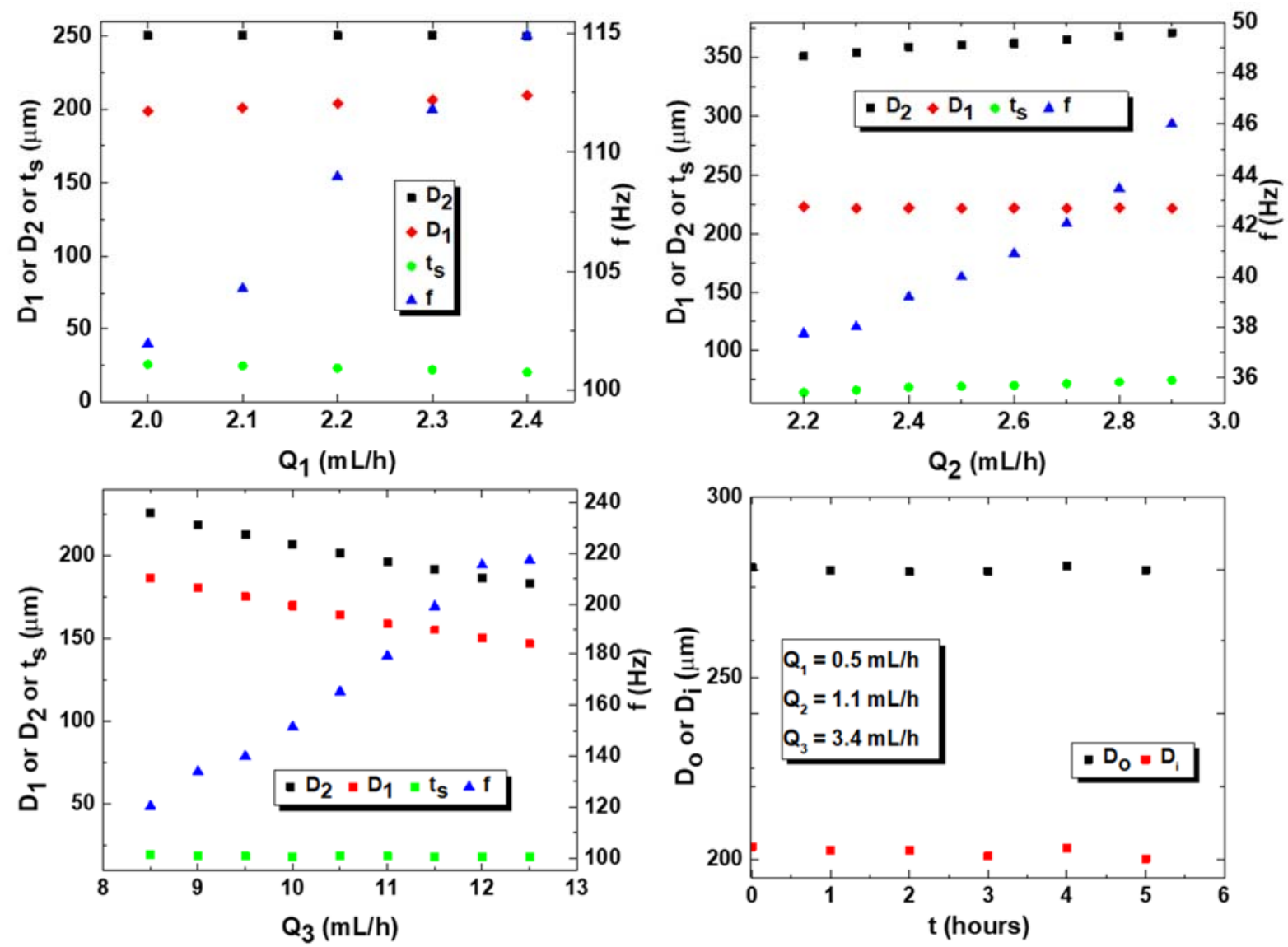

Figure 3. The effect of fluid flow rates on the diameters of inner and outer droplets, $D_{1}$ and $D_{2}$, and generation frequency, $f$ of $\mathrm{W}_{1} / \mathrm{O} / \mathrm{W}_{2}$ emulsion formed in dripping regime at $D_{N}=50 \mu \mathrm{m}$ and $D_{\text {orif }}=250 \mu \mathrm{m}$ : (a) $Q_{2}=1.4 \mathrm{~mL} / \mathrm{h}$ and $Q_{3}=7 \mathrm{~mL} / \mathrm{h}$; (b) $Q_{1}=1.2 \mathrm{~mL} / \mathrm{h}$ and $Q_{3}=5$ $\mathrm{mL} / \mathrm{h}$; (c) $Q_{1}=2 \mathrm{~mL} / \mathrm{h}$ and $Q_{2}=1.4 \mathrm{~mL} / \mathrm{h}$. (d) The variations of droplet diameters during continuous droplet generation over $5 \mathrm{~h}$. All droplet diameters are the average values from 20 measurements with $C V<3 \%$. The emulsion formulation is the same as in Figure 2.

The droplet generation behavior was stable over at least five hours, as shown in Fig. 3d. There was no noticeable change in the diameter of the produced droplets and the frequency of droplet generation. No wetting of the capillary walls was observed over $5 \mathrm{~h}$, indicating that the surface treatment of glass wall by organosilicon compounds was robust.

The collected core/shell droplets are shown in Figure 4. In Fig. 4a, one small satellite droplet of internal aqueous phase was enclosed within each oil droplet in addition to the main aqueous drop. As the jet starts to pinch off it creates a neck between the jet and the developing drop. Satellite droplets are formed because the neck breaks up at multiple locations during jet pinch-off (Nabavi et al. 2015b). 


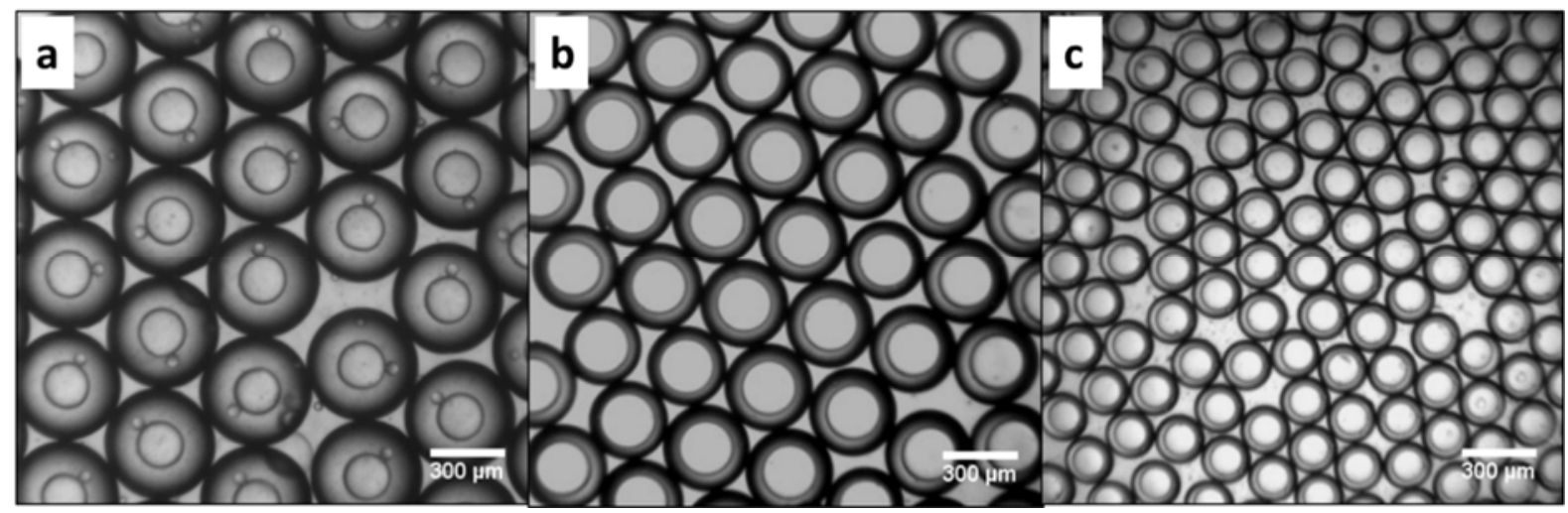

Figure 4. Microscopic images of $\mathrm{W} / \mathrm{O} / \mathrm{W}$ droplets with different sizes and shell thicknesses generated at: (a) $Q_{1}=0.2 \mathrm{~mL} / \mathrm{h}, Q_{2}=2.5 \mathrm{~mL} / \mathrm{h}, Q_{3}=5 \mathrm{~mL} / \mathrm{h}\left(C V=0.7 \%, D_{2}=450 \mu \mathrm{m}, D_{1}\right.$ $\left.=190 \mu \mathrm{m}, t_{s}=131 \mu \mathrm{m}\right)$; (b) $Q_{1}=0.3 \mathrm{~mL} / \mathrm{h}, Q_{2}=1 \mathrm{~mL} / \mathrm{h}, Q_{3}=3.8 \mathrm{~mL} / \mathrm{h}\left(C V=0.9 \%, D_{2}=\right.$ $\left.343 \mu \mathrm{m}, D_{1}=211 \mu \mathrm{m}, t_{s}=66 \mu \mathrm{m}\right)$; (c) $Q_{1}=0.5 \mathrm{~mL} / \mathrm{h}, Q_{2}=1.5 \mathrm{~mL} / \mathrm{h}, Q_{3}=3.4 \mathrm{~mL} / \mathrm{h}(C V=$ $\left.1.2 \%, D_{2}=198 \mu \mathrm{m}, D_{1}=116 \mu \mathrm{m}, t_{s}=41 \mu \mathrm{m}\right)$. The inner phase was $1.5 \mathrm{wt} \% \mathrm{NaCl}$ and 50 $\mathrm{wt} \%$ sucrose in water, the middle phase was $2.86 \mathrm{wt} \%$ PGPR in sunflower oil, and the outer phase was $25 \mathrm{wt} \%$ sucrose and $4 \mathrm{wt} \%$ starch in water.

The shell thickness depends on the middle phase to inner phase flow rate ratio, $Q_{2} / Q_{1}$, during droplet generation and the size of inner droplets, $D_{1}$ :

$$
t_{s}=\frac{D_{1}}{2}\left\{\left[1+\left(\frac{Q_{2}}{Q_{1}}\right)^{1 / 3}\right]-1\right\}
$$

In Fig. 4a, $Q_{2} / Q_{1}$ was 12.5 leading to thicker shell than in Figs. $4 \mathrm{~b}$, when $Q_{2} / Q_{1}$ was 3. Under similar flow rates, the droplets stabilized by OSA starch (Fig. 4c) were noticeably smaller than the droplets stabilized by waxy rice starch (Fig. 4b), which can be attributed to the amphiphilic and thereby the interfacial tension reducing character of OSA-modified starch, due to the introduction of hydrophobic alkenyl groups of OSA, while the waxy rice starch was heat treated and does not have the ability to reduce the interfacial tension (Kasprzak et al. 2018). The higher interfacial tension at the external oil-water led to the higher ability of the compound jet to resist break up during pinch-off resulting in larger droplets (Nabavi et al. 2015).

\subsection{Encapsulation efficiency and storage stability of emulsions}

Emulsion stability is a critical factor in the food industry as most of the food emulsions are stored after production. In this case, emulsifiers should stabilize both oil-water interfaces during storage but should impart instability during oral processing to provide a burst release of 
sugar in the vicinity of taste buds. Core/shell droplets stabilized with $2.86 \mathrm{wt} \%$ PGPR in the middle phase and $4 \mathrm{wt} \%$ OSA starch in the outer phase coalesced after $\sim 1 \mathrm{~h}$. However, core/shell droplets containing $1.4 \mathrm{wt} \%$ or $2.86 \mathrm{wt} \%$ PGPR and $4 \mathrm{wt} \%$ gelatinized starch were stable over 60 days (Table 1). The droplet stability in the presence of gelatinized starch was achieved in spite of an osmotic gradient of $\sim 513 \mathrm{mOsmol}$ induced by the salt addition to the internal droplets, which is more than 2.5 times higher than the recommended osmotic gradient (180-200 mOsmol) for obtaining stable multiple emulsions (Muschiolik et al. 2006).

Table 1. The efficiency of encapsulation, release of sucrose during in-vitro digestion with $\alpha$ amylase, and stability against coalescence for different emulsion samples. The inner phase was $1.5 \mathrm{wt} \% \mathrm{NaCl}$ and $50 \mathrm{wt} \%$ sucrose in water, the middle phase was PGPR in sunflower oil, and the outer phase was $25 \mathrm{wt} \%$ sucrose and $4 \%$ gelatinised waxy rice starch in water.

\begin{tabular}{|c|c|c|c|c|c|}
\hline \multirow{2}{*}{$\begin{array}{l}\text { PGPR content in the middle } \\
\text { phase and emulsion type }\end{array}$} & \multirow{2}{*}{$\begin{array}{l}\text { EE } \\
(\%)\end{array}$} & \multirow{2}{*}{$\begin{array}{c}\text { Sucrose release } \\
\text { during digestion } \\
(\%)\end{array}$} & \multicolumn{3}{|c|}{ Emulsion stability } \\
\hline & & & Day1 & Day7 & Day60 \\
\hline $2.86 \mathrm{wt} \% \mathrm{PGPR}, \mathrm{W}_{1} / \mathrm{O} / \mathrm{W}_{2}{ }^{+}$ & 100 & $16 \pm 3$ & $\checkmark$ & $\checkmark$ & $\checkmark$ \\
\hline $2.86 \mathrm{wt} \%$ PGPR, $\left(\mathrm{W}_{1} / \mathrm{O}\right) / \mathrm{W}_{2}{ }^{\dagger+}$ & 100 & $91 \pm 10$ & $x$ & $x$ & $x$ \\
\hline $1.4 \mathrm{wt} \%, \mathrm{PGPR}, \mathrm{W}_{1} / \mathrm{O} / \mathrm{W}_{2}{ }^{*}$ & 99 & $53 \pm 4$ & $\checkmark$ & $\checkmark$ & $\checkmark$ \\
\hline $0.7 \mathrm{wt} \% \mathrm{PGPR}, \mathrm{W}_{1} / \mathrm{O} / \mathrm{W}_{2}{ }^{* *}$ & 70 & $49 \pm 10$ & $x$ & $x$ & $x$ \\
\hline
\end{tabular}

${ }^{\dagger} D_{i}=158 \mu \mathrm{m}, D_{o}=275 \mu \mathrm{m}, t_{s}=58 \mu \mathrm{m} ;{ }^{+\dagger} D_{d}=291 \mu \mathrm{m} ;{ }^{*} D_{i}=164 \mu \mathrm{m}, D_{o}=247 \mu \mathrm{m}, t_{s}=$ $42 \mu \mathrm{m} ;{ }^{* *} D_{i}=187 \mu \mathrm{m}, D_{o}=305 \mu \mathrm{m}, t_{s}=59 \mu \mathrm{m}$.

$\checkmark$ : denotes stable emulsion; $\boldsymbol{x}$ denotes unstable emulsion.

All the results in the table present the average value of three replicates taken for two samples which were collected at different times during the emulsion formation process.

High stability of core/shell droplets in the presence of gelatinized starch can be explained by high degree of association of starch molecules after thermal treatment due to realignment of amylose and amylopectin. These large hydrogen-bonded aggregates with a molecular weight $M_{w}$ of $91.9 \mathrm{MDa}$ (Kasprzak et al. 2018) adhered to the external droplet interface forming a thick interfacial layer that imparted a long-term stability to the droplets. On the other hand, after esterification of starch with OSA, steric hindrance effects imposed by bulky OSA groups prevent the alignment of molecular chains of starch resulting in a small degree of association between starch molecules and a $M_{w}$ of $0.47 \mathrm{MDa}$ (Kasprzak et al. 2018). As a result, OSAwaxy maize starch (NC46) can easily diffuse to the external interface due to its small amphiphilic molecules forming a thin interfacial layer. Interestingly, $4 \mathrm{wt} \%$ OSA starch was 
able to impart a long-term stability to an $\mathrm{O} / \mathrm{W}$ emulsion with a droplet size of several microns (Kasprzak et al. 2018).

To estimate the encapsulation efficiency of sucrose, a freshly prepared emulsion was gently mixed and its electric conductivity was measured and used to estimate the amount of salt in the external aqueous phase. The encapsulation efficiency, $E E$ was calculated as:

$$
E E=\left(m_{1}-m_{2}\right) / m_{1}
$$

where $m_{1}$ is the mass of $\mathrm{NaCl}$ added to the inner phase and $m_{2}$ is the mass of $\mathrm{NaCl}$ in the external phase after emulsion collection. The $E E$ was $\sim 100 \%$ for all of the formulations except when the content of PGPR in the middle phase was $0.7 \mathrm{wt} \%$ (Table 1 ) suggesting that $0.7 \mathrm{wt} \%$ PGPR was not enough to stabilize the droplets and thus $30 \%$ of the salt was released during emulsion preparation. This finding agreed with the stability test results, since coalescence of oil droplets was observed on day 1. High encapsulation efficiencies of small molecules within core-shell droplets were observed in many microfluidic devices (Li et al. 2018).

Typical instability mechanisms and release pathways involved in a $\mathrm{W} / \mathrm{O} / \mathrm{W}$ emulsion are the expulsion of internal droplets into the external phase, the coalescence of internal droplets before expulsion from multiple emulsion drops, and the shrinkage or swelling of internal droplets due to osmotic pressure gradient across the oil phase (Benichou \& Aserin 2008; Florence \& Whitehill 1981). In this case, the expulsion of internal droplets was most likely responsible for the low $E E$ value at $0.7 \mathrm{wt} \%$ PGPR. Therefore, the PGPR content in the oil phase should be at least $1.4 \mathrm{wt} \%$ to impart droplet stability during microfluidic emulsification and subsequent storage.

Multiple emulsion droplets containing numerous small internal droplets with a mean diameter of about $4 \mu \mathrm{m}$ showed 100\% EE during microfluidic emulsification but very poor storage stability (Table 1). In core/shell droplets, swelling of internal droplets was suppressed by the relatively thick oil layer around the internal water droplets. The diffusion of water is inversely proportional to the shell thickness, which was $42-58 \mu \mathrm{m}$ for the droplets in Table 1. In multiple emulsion droplets with numerous small internal droplets, some internal droplets were located very close to the external interface, which led to fast swelling of internal droplets and their burst from the oil phase. $\left(\mathrm{W}_{1} / \mathrm{O}\right) / \mathrm{W}_{2}$ emulsions containing $1-2 \mathrm{wt} \%$ PGPR and 1-4 wt\% gelatinized waxy rice starch prepared by Kasprzak et al. (2019) using a high-shear mixer showed a high long-term stability, which means that stability of multiple emulsions during storage under stagnant conditions strongly depends on droplet size, probably due to different creaming rates. 


\subsection{Release of sucrose during in-vitro digestion}

To study the release of sucrose during digestion, an in-vitro oral cavity model was used. Core/shell droplets stabilized with OSA starch burst shortly after fabrication and were not used here. In addition, OSA starch is less accessible to salivary amylase compared to native starch and shows a lower digestion kinetics (He et al. 2008; Lin et al. 2018).

The sucrose release was calculated as:

$$
\text { sucrose release }(R)=\left(m_{2}-m_{3}\right) /\left(m_{1}-m_{2}\right)
$$

where $m_{3}$ is the mass of $\mathrm{NaCl}$ in the internal droplets after digestion.

The highest release of sucrose was observed in $\left(\mathrm{W}_{1} / \mathrm{O}\right) / \mathrm{W}_{2}$ emulsion (Table 1$)$, which agreed with the fact that this emulsion showed signs of coalescence after one day of storage. Core/shell droplets stabilized with $2.86 \mathrm{wt} \%$ PGPR released only $16 \%$ of sucrose during digestion, which can be explained by the synergistic stabilizing effect of PGPR and $\mathrm{NaCl}$. There are many evidences that the presence of salt in the aqueous phase increases the stability of PGPR-stabilized W/O/W and W/O emulsions (Márquez et al. 2010). The salt seems to increase the elasticity of interfacial PGPR films and decrease its hydrophilic-lipophilic balance (HLB) value by depleting the hydration shell around hydrophilic polyglycerol moieties and thus, promoting hydrophobic interactions between PGPR chains. In real applications, the salt content in the inner phase will be lower, which will likely lead to higher release of sucrose compared to the amount of sucrose released in this work.

Core/shell droplets containing 1.4 wt\% PGPR in the shell were less stable, releasing 53 $\%$ of sugar. Decreasing PGPR concentration decreases the interfacial tension at both oil-water interfaces and lowers the middle phase viscosity, which leads to enhanced coalescence of both internal and external droplets. Core/shell droplets stabilized with $0.7 \mathrm{wt} \%$ PGPR released 49 $\%$ of sucrose during digestion, but the total amount of sugar released during emulsification and oral processing was higher than with $1.4 \mathrm{wt} \%$ PGPR in the middle phase.

Micrographs of emulsion samples before and after digestion are shown in Figure 5. Coreshell droplets stabilized with $2.86 \mathrm{wt} \%$ PGPR were monodispersed prior to in-vitro digestion (Fig. 5a). After digestion, three different droplet morphologies can be distinguished: the original droplets with core-shell morphology that survived the treatment, small oil droplets with a diameter of $110 \mu \mathrm{m}$ formed due to bursting of oil shells and large oil droplets formed 
by coalescence of original oil droplets due to mechanical action and enzymatic reaction during simulated oral processing (Fig 5. b-c). In the ( $\left.\mathrm{W}_{1} / \mathrm{O}\right) / \mathrm{W}_{2}$ emulsion sample (Fig. 5d), phase inversion was detected. The $\left(\mathrm{W}_{1} / \mathrm{O}\right) / \mathrm{W}_{2}$ emulsion was inverted into $\mathrm{W}_{2} /\left(\mathrm{W}_{1} / \mathrm{O}\right)$ with large water droplets, with a diameter larger than $400 \mu \mathrm{m}$, dispersed in the $\mathrm{W}_{1} / \mathrm{O}$ emulsion. In the case of the $\mathrm{W}_{1} / \mathrm{O} / \mathrm{W}_{2}$ emulsion with $1.4 \mathrm{wt} \%$ PGPR (Fig. 5 e-f), a higher degree of coalescence was detected than when $2.86 \mathrm{wt} \%$ PGPR was used.
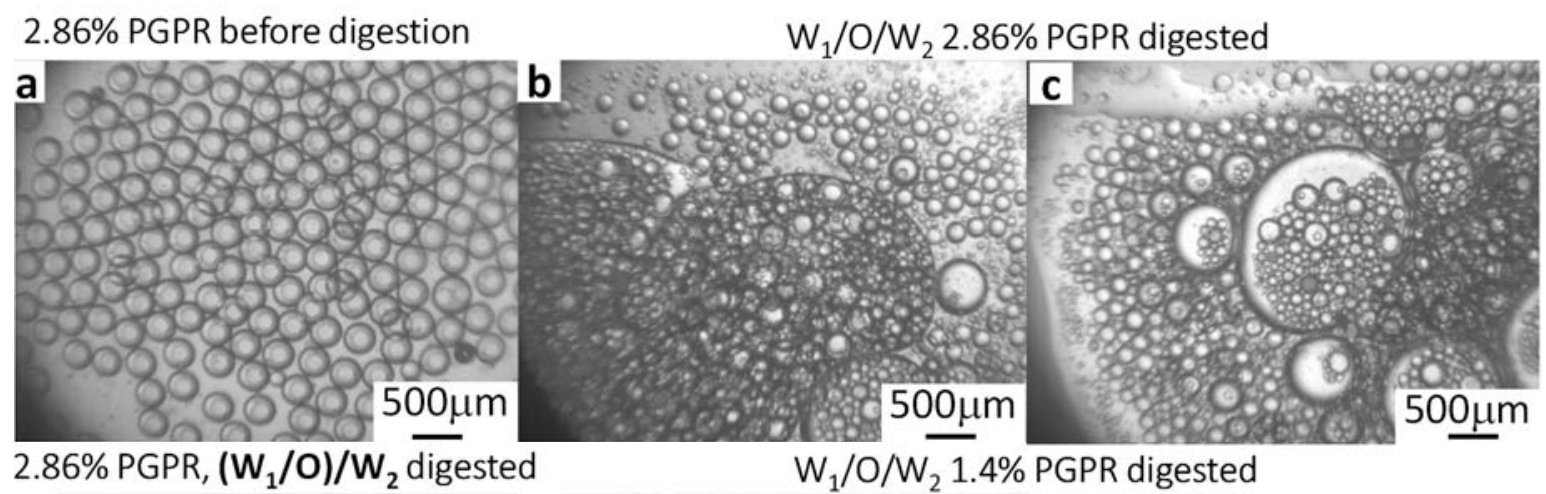

$\mathrm{W}_{1} / \mathrm{O} / \mathrm{W}_{2} 1.4 \%$ PGPR digested

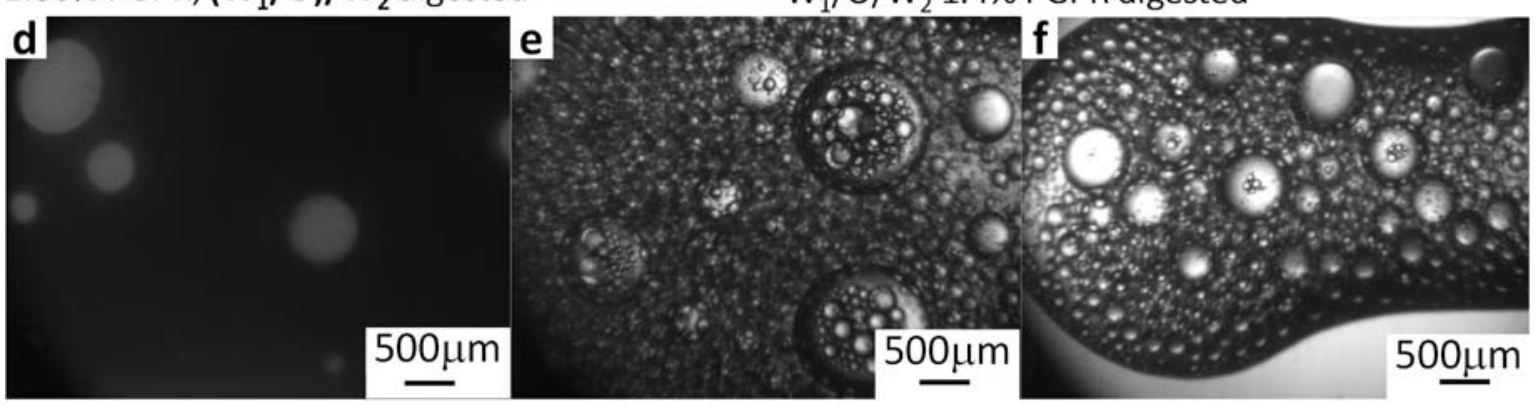

Figure 5. Micrographs of emulsion droplets before and after in-vitro oral digestion: (a) $\mathrm{W}_{1} / \mathrm{O} / \mathrm{W}_{2}$ emulsion with $2.86 \mathrm{wt} \%$ PGPR in the middle phase before digestion; (b-c) $\mathrm{W}_{1} / \mathrm{O} / \mathrm{W}_{2}$ emulsion with $2.86 \mathrm{wt} \%$ PGPR in the middle phase after digestion; (d) $\left(\mathrm{W}_{1} / \mathrm{O}\right) / \mathrm{W}_{2}$ emulsion with $2.86 \mathrm{wt} \%$ PGPR in the middle phase after digestion; (e-f): $\mathrm{W}_{1} / \mathrm{O} / \mathrm{W}_{2}$ emulsion with 1.4 $w t \%$ PGPR in the middle phase after digestion.

\section{Conclusion}

Monodispersed $\mathrm{W}_{1} / \mathrm{O} / \mathrm{W}_{2}$ emulsions consisting of starch-coated oil shells and aqueous cores loaded with concentrated sucrose solution were successfully generated in a microfluidic device. The droplet generation was stable for over $5 \mathrm{~h}$ and the size and morphology of the droplets were controlled by varying fluid flow rates. A multiple emulsion consisting of numerous tiny internal droplets stabilized with $2.86 \mathrm{wt} \%$ PGPR broke down rapidly during invitro oral processing, releasing almost all sugar from the internal droplets, which is beneficial to boost the sweetness perception, but the emulsion droplets coalesced after 1-day storage. The 
emulsion instability during in-vitro digestion with $\alpha$-amylase could be related with the facility of this enzyme to be absorbed to the interface of this emulsion.

Core/shell droplets showed higher stability against coalescence than oil droplets with numerous tiny internal droplets. However, only $16 \%$ of sucrose was released during in-vitro digestion from the core-shell droplets containing $2.86 \mathrm{wt} \%$ PGPR in the shell. Such a low sucrose release rate could also be attributed to the stabilizing effect of added $\mathrm{NaCl}$. Reducing the PGPR content in the oil phase improved sucrose release, but the encapsulation efficiency of sucrose was also reduced. The use of molecularly dispersed OSA-modified starch instead of gelatinized starch led to production of smaller droplets, due to lower interfacial tension in the presence of interfacially active starch. On the other hand, gelatinized starch imparted a longterm storage stability due to adherence of its large insoluble aggregates onto the external droplet surface, which led to the formation of thicker interfacial layer.

The sugar contents applied in this study were selected to evaluate the feasibility of this sweetness-enhancing technology. The sugar content in the actual food product will depend on the proportion of internal emulsion in the final formulation and can be freely adjusted.

\section{Acknowledgment}

MK and BW acknowledge support by the Biotechnology and Biological Sciences Research Council [grant number BB/M027139/1]. Ruqaiya Al Nuumani holds a scholarship from 'The Government of Oman'. GTV acknowledges support received from the Engineering and Physical Sciences Research Council [grant number EP/HO29923/1].

\section{References}

Abate, A. R., Thiele, J. and Weitz, D. A. (2011) 'One-step formation of multiple emulsions in microfluidics', Lab on a Chip, 11(2), pp. 253-258. doi: 10.1039/c01c00236d.

Al nuumani, R., Bolognesi, G. and Vladisavljević, G.T. (2018) 'Microfluidic production of poly(1,6-hexanediol diacrylate)-based polymer microspheres and bifunctional microcapsules with embedded $\mathrm{TiO}_{2}$ nanoparticles', Langmuir, 34(39), pp. 11822-11831. doi: 10.1021/acs.langmuir.8b02452.

Bandulasena, M.V., Vladisavljević, G.T. and Benyahia, B. (2019): 'Versatile reconfigurable 
glass capillary microfluidic devices with Lego ${ }^{\circledR}$ inspired blocks for drop generation and micromixing', Journal of Colloid and Interface Science, 542, pp. 23-32. doi:

10.1016/j.jcis.2019.01.119

Benichou, A. and Aserin, A. (2008) 'Recent developments in O/W/O multiple emulsions'. In: Multiple Emulsions: Technology and Applications, Ed. Aserin, A. (John Wiley \& Sons, Inc: Hoboken, New Jersey, pp. 165-208.

Benichou, A., Aserin, A. and Garti, N. (2004) 'Double emulsions stabilized with hybrids of natural polymers for entrapment and slow release of active matters', Advances in Colloid and Interface Science, 108-109, pp. 29-41. doi: 10.1016/j.cis.2003.10.013.

Burseg, K.M.M., Lieu, H.L. and Bult, J.H.F. (2012) ' Sweetness intensity enhancement by pulsatile stimulation: effects of magnitude and quality of taste contrast', Chemical Senses, 37(1), pp. 27-33. doi: 10.1093/chemse/bjr062.

Buyukkestelli, H. I. and Nehir El, S. (2019) 'Preparation and characterization of double emulsions for saltiness enhancement by inhomogeneous spatial distribution of sodium chloride', LWT - Food Science and Technology, 101, pp. 229-235. doi: 10.1016/j.lwt.2018.10.086.

Chiu , N., Hewson, L., Fisk, I. and Wolf, B. (2015) 'Programmed emulsions for sodium reduction in emulsion based foods', Food \& Function, 6(5), pp. 1428-1434. doi: 10.1039/C5FO00079C.

Dickinson, E. (2011) 'Double emulsions stabilized by food biopolymers', Food Biophysics, 6(1), pp. 1-11. doi: 10.1007/s11483-010-9188-6.

Florence, A. T. and Whitehill, D. (1981) 'Some features of breakdown in water-in-oil-inwater multiple emulsions', Journal of Colloid and Interface Science, 79(1), pp. 243-256. doi: 10.1016/0021-9797(81)90066-7.

Florence, A. T. and Whitehill, D. (1982) 'The formulation and stability of multiple emulsions', International Journal of Pharmaceutics, 11(4), pp. 277-308. doi: 10.1016/03785173(82)90080-1.

He, J., Liu, J. and Zhang, G. (2008) 'Slowly digestible waxy maize starch prepared by octenyl succinic anhydride esterification and heat-moisture treatment: Glycemic response and mechanism', Biomacromolecules, 9(1), 175-184. doi: 10.1021/bm700951s.

Jiménez-Colmenero, F. (2013) 'Potential applications of multiple emulsions in the development of healthy and functional foods', Food Research International, 52(1), pp. 6474. doi: 10.1016/j.foodres.2013.02.040. 
Kasprzak, M. M., Macnaughtan, W, Harding, S., Wilde, P. and Wolf, B. (2018) 'Stabilisation of oil-in-water emulsions with non-chemical modified gelatinised starch', Food Hydrocolloids, 81, pp. 409-418. doi: 10.1016/j.foodhyd.2018.03.002.

Kasprzak, M., Wilde, P., Hill, S. E., Harding, S. E., Ford, R. and Wolf, B. (2019) Nonchemically modified waxy rice starch stabilised wow emulsions for salt reduction, Food \& Function, 10, pp. 4242-4255. doi: 10.1039/c8fo01938j.

Knüppel, A., Shipley, M. J., Llewellyn, C. H. and Brunner, E. J. (2017) 'Sugar intake from sweet food and beverages, common mental disorder and depression: Prospective findings from the Whitehall II study', Scientific Reports, 7(1), pp. 1-10. doi: 10.1038/s41598-01705649-7.

Kukizaki, M. and Goto, M. (2007) 'Preparation and evaluation of uniformly sized solid lipid microcapsules using membrane emulsification', Colloids and Surfaces A: Physicochemical and Engineering Aspects, 293(1-3), pp. 87-94. doi: 10.1016/j.colsurfa.2006.07.011.

Lad, M., Hewson, L. and Wolf, B. (2012) 'Enhancing saltiness in emulsion based foods', Flavour, 1, 13. doi: 10.1186/2044-7248-1-13.

Lamba, H., Sathish, K. and Sabikhi, L. (2015) 'Double emulsions: Emerging delivery system for plant bioactives', Food and Bioprocess Technology, 8(4), pp. 709-728. doi: 10.1007/s11947-014-1468-6.

Li, W., Zhang, L., Ge, X., Xu, B., Zhang, W., Qu, L., Choi, C. H., Xu, J., Zhang, A., Lee, H. and Weitz, D. A. (2018): 'Microfluidic fabrication of microparticles for biomedical applications', Chemical Society Reviews, 47, pp. 5646--5683. doi: 10.1039/c7cs00263g. Lin, Q., Liang, R., Zhong, F., Ye, A. and Singh, H. (2018) 'Effect of degree of octenyl succinic anhydride (OSA) substitution on the digestion of emulsions and the bioaccessibility of $\beta$-carotene in OSA-modified-starch-stabilized-emulsions ', Food Hydrocolloids, 84, pp. 303-312. doi: 10.1016/j.foodhyd.2018.05.056.

Márquez, A. L., Medrano, A., Panizzolo, L. A. and Wagner, J. R. (2010) 'Effect of calcium salts and surfactant concentration on the stability of water-in-oil (w/o) emulsions prepared with polyglycerol polyricinoleate', Journal of Colloid and Interface Science, 341, 101-108. doi: 10.1016/j.jcis.2009.09.020.

McClements, D. J. (2005) Food emulsions: principles, practices, and techniques. Second. New York: CRC Press.

McClements, D. J., Decker, E. A. and Weiss, J. (2007) 'Emulsion-based delivery systems for lipophilic bioactive components', Journal of Food Science, 72(8), pp. 109-124. doi: 10.1111/j.1750-3841.2007.00507.x. 
Muschiolik, G., Scherze, I., Preissler P., Weiß, J., Knoth, A. and Fechner A. (2006) 'Fechner, Multiple emulsions - preparation and stability', 13th World Congress of Food Science \& Technology, pp. 123-137. doi: 10.1051/IUFoST:20060043.

Muschiolik, G. (2007) 'Multiple emulsions for food use', Current Opinion in Colloid and Interface Science, 12(4-5), pp. 213-220. doi: 10.1016/j.cocis.2007.07.006.

Muschiolik, G. and Dickinson, E. (2017) 'Double emulsions relevant to food systems: preparation, stability, and applications', Comprehensive Reviews in Food Science and Food Safety, 16(3), pp. 532-555. doi: 10.1111/1541-4337.12261.

Nabavi, A. S., Vladisavljević, G. T., Gu, S. and Ekanem, E. E. (2015) 'Double emulsion production in glass capillary microfluidic device: Parametric investigation of droplet generation behaviour', Chemical Engineering Science, 130, pp. 183-196. doi: 10.1016/j.ces.2015.03.004.

Nabavi, A. S., Gu, S., Vladisavljević, G. T. and Ekanem, E. E. (2015b) 'Dynamics of double emulsion break-up in three phase glass capillary microfluidic devices', Journal of Colloid and Interface Science, 450, pp. 279-287. doi: 10.1016/j.jcis.2015.03.032.

Nabavi, S. A., Vladisavljević, G. T. and Manović, V. (2017) 'Mechanisms and control of single-step microfluidic generation of multi-core double emulsion droplets', Chemical Engineering Journal, 322, pp. 140-148. doi: 10.1016/j.cej.2017.04.008.

Nabavi, S. A., Vladisavljević, G. T., Bandulasena, M. V., Arjmandi-Tash, O. and Manović, V. (2017b) 'Prediction and control of drop formation modes in microfluidic generation of double emulsions by single-step emulsification', Journal of Colloid and Interface Science, 505, pp. 315-324. doi: 10.1016/j.jcis.2017.05.115.

Norton, J. E. and Norton, I. T. (2010) 'Designer colloids - Towards healthy everyday foods?', Soft Matter, 6(16), pp. 3735-3742. doi: 10.1039/c001018a.

Okushima, S., Nisisako, T, Torii, T. and Higuchi T. (2004) 'Controlled production of monodisperse double emulsions by two-step droplet breakup in microfluidic devices', Langmuir, 20(23), pp. 9905-9908. doi: 10.1021/la0480336.

Sun, B. J., Shum, H. C., Holtze, C. and Weitz, D. A. (2010) 'Microfluidic melt emulsification for encapsulation and release of actives', Applied Materials \& Interfaces, 2(12), pp. 34113416. doi: 10.1021/am100860b.

Vladisavljević, G. T., Kobayashi, I. and Nakajima, M. (2012) 'Production of uniform droplets using membrane, microchannel and microfluidic emulsification devices', Microfluidics and Nanofluidics, 13(1), pp. 151-178. 
Vladisavljević, G. T., Al Nuumani, R. and Nabavi, S. A. (2017) 'Microfluidic production of multiple emulsions', Micromachines, 8(3), pp. 1-34. doi: 10.3390/mi8030075.

Vladisavljević, G. T., Ekanem, E. E., Zhang, Z., Khalid, N., Kobayashi, I. and Nakajima, M. (2018) 'Long-term stability of droplet production by microchannel (step) emulsification in microfluidic silicon chips with large number of terraced microchannels', Chemical Engineering Journal, 333, pp. 380-391. doi: 10.1016/j.cej.2017.09.141. 